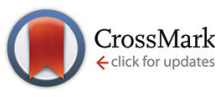

Cite this: Org. Biomol. Chem., 2017, 15,559

Received 16th November 2016, Accepted 29th November 2016

DOI: $10.1039 / c 6 o b 02498 j$

www.rsc.org/obc

\section{Conformationally superarmed $S$-ethyl glycosyl donors as effective building blocks for chemoselective oligosaccharide synthesis in one pot $\uparrow$}

\author{
Mithila D. Bandara, ${ }^{a}$ Jagodige P. Yasomanee, ${ }^{a}$ Nigam P. Rath, ${ }^{a}$ \\ Christian M. Pedersen, ${ }^{\mathrm{b}}$ Mikael Bols ${ }^{\mathrm{b}}$ and Alexei V. Demchenko ${ }^{{ }^{a}}$
}

\begin{abstract}
A new series of superarmed glycosyl donors has been investigated. It was demonstrated that the $S$-ethyl leaving group allows for high reactivity, which is much higher than that of equally equipped $S$-phenyl glycosyl donors that were previously investigated by our groups. The superarmed $S$-ethyl glycosyl donors equipped with a 2-O-benzoyl group gave complete $\beta$-stereoselectivity. Utility of the new glycosyl donors has been demonstrated in a one-pot one-addition oligosaccharide synthesis with all of the reaction components present from the beginning.
\end{abstract}

Mechanistic challenges in the chemical glycosylation reaction have consistently captured the attention of the synthetic community. ${ }^{1}$ Many classes of glycosyl donors have been developed ${ }^{2}$ and many strategies for oligosaccharide synthesis have emerged. ${ }^{3}$ Among the methods and strategies available, the development of the armed-disarmed strategy for chemoselective oligosaccharide synthesis occupies an important niche. ${ }^{4}$ Reactivity tuning of various series of thioglycosides has been reported and applied to the synthesis of a variety of oligosaccharide sequences. ${ }^{5}$ Beyond the traditional scope of the armed-disarmed strategy, superarmed and superdisarmed building blocks have also been identified and studied. ${ }^{6}$ Bols and co-workers developed an approach to superarm glycosyl donors by changing the equatorial-rich ${ }^{4} \mathrm{C}_{1}$ conformation to an axial-rich conformation. ${ }^{7}$ These conformational changes were induced by creating steric congestion with tert-butyldimethylsilyl (TBS) or related bulky protecting groups at the C-2, 3 and 4 positions of $S$-phenyl (SPh) glucosides, resulting in a skewboat conformation. The donors showed a 20 -fold increase in reactivity compared to their armed per-O-benzylated counter-

\footnotetext{
${ }^{a}$ Department of Chemistry and Biochemistry, University of Missouri - St. Louis, One University Boulevard, St. Louis, Missouri 63121, USA.

E-mail: demchenkoa@umsl.edu

${ }^{b}$ Department of Chemistry, University of Copenhagen, 2100 Copenhagen Ø, Denmark $\dagger$ Electronic supplementary information (ESI) available: Experimental details, characterization data, ${ }^{1} \mathrm{H}$ and ${ }^{13} \mathrm{C}$ NMR spectra for all new compounds as well as X-ray data for 10. CCDC 1509777. For ESI and crystallographic data in CIF or other electronic format see DOI: 10.1039/c6ob02498j
}

parts. $^{7 c}$ The Demchenko group also reported superarmed $S$-benzoxazolyl (SBox) and $S$-ethyl (SEt) glycosyl donors, but the superarming was based on the $\mathrm{O} 2 / \mathrm{O} 5$-cooperative effect in glycosylation. $^{8}$ Thus, it was demonstrated that donors equipped with the 2-O-benzoyl-3,4,6-tri-O-benzyl protecting group pattern are 10 times more reactive than their armed counterparts. ${ }^{9}$

Using the two different approaches to superarm glycosyl donors, our groups jointly developed a 2-O-benzoyl donor $\mathbf{1}$ with 3,4-di-O-TBS protection (Scheme 1). Over the course of that study we learned that conformational arming is a powerful tool for increasing reactivity and achieving excellent yields and the 2-O-benzoyl substituent ensured complete 1,2-trans stereoselectivity. ${ }^{10}$ The anchimeric superarming effects in the conformationally modified donor $\mathbf{1}$ are significantly weaker, to the extent that the 2-O-benzoylated SPh donor 1 is 5.8 and 4.5 times less reactive than its 2-O-TBS and 2-O-benzylated counterparts 2 and 3, respectively (Scheme 1). Although glycosylations with hybrid donor 1 were swift, high yielding and $\beta$-stereoselective, ${ }^{10}$ we feared that the reduced reactivity could

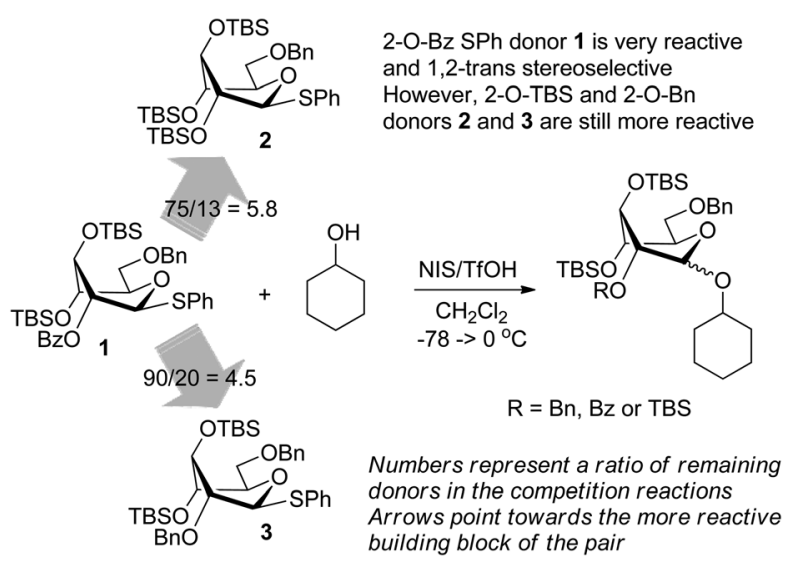

Scheme 1 The relative reactivity of the conformationally superarmed S-phenyl glycosyl donors. ${ }^{10}$ 
translate into decreased efficacy of these building blocks in sequential chemoselective glycosylations in one-pot. This led us to a hypothesis that the use of a more reactive $S$-ethyl leaving group ${ }^{11}$ would help us to develop a complementary superarmed glycosyl donor with a superior reactivity profile whilst still maintaining $\beta$-stereoselectivity.

Right from the start, when donor 1 was subjected to a competition experiment with the equally protected SEt donor 5, a much higher reactivity of the latter was detected. The competition experiments for this study were conducted following essentially the same experimental conditions and ratios as in our previous study. ${ }^{10}$ Two glycosyl donors, used in equimolar amounts (1.0 equiv. each), were set to compete for excess glycosyl acceptor $4^{12}$ (2.0 equiv.) in the presence of NIS (1.0 equiv.) and $\mathrm{TfOH}\left(0.1\right.$ equiv.) at $-78^{\circ} \mathrm{C}$. The use of low temperature, which was allowed to gradually increase over the course of the reaction, and the use of a very limited amount of promoter helped to maintain workable reaction rates. All of the competition experiments were quenched after $1 \mathrm{~h}$ and the remaining glycosyl donors were isolated and quantified. Thus, as a result of the first competition experiment, SPh donor 1 remained the major monosaccharide component of the mixture and was isolated in $87 \%$ yield, whereas only $13 \%$ of the SEt donor 5 remained (Scheme 2). This translates into a $1 / 6.7$ reactivity ratio between the two donors, or in other words, the SEt donor 5 is 6.7 times more reactive than its SPh counterpart 1.

Subsequent competition experiments led to the realization that 2-O-benzoyl SEt donor 5 is nearly as reactive as 2-O-benzyl SPh donor $3(1 / 1.1)$ and only slightly less reactive than the most reactive superarmed 2-O-TBS protected SPh donor 2 known to date (1/1.6, Scheme 2$)$. To explore the reactivity limits of superarmed glycosyl donors of the SEt series, we obtained donor 6 equipped with the 2-O-benzyl protecting group. A competition experiment with equally protected SPh donor 3 led to the realization of the higher reactivity of donor $6(3 / 6=1 / 3.8)$. Using a similar approach, we determined that

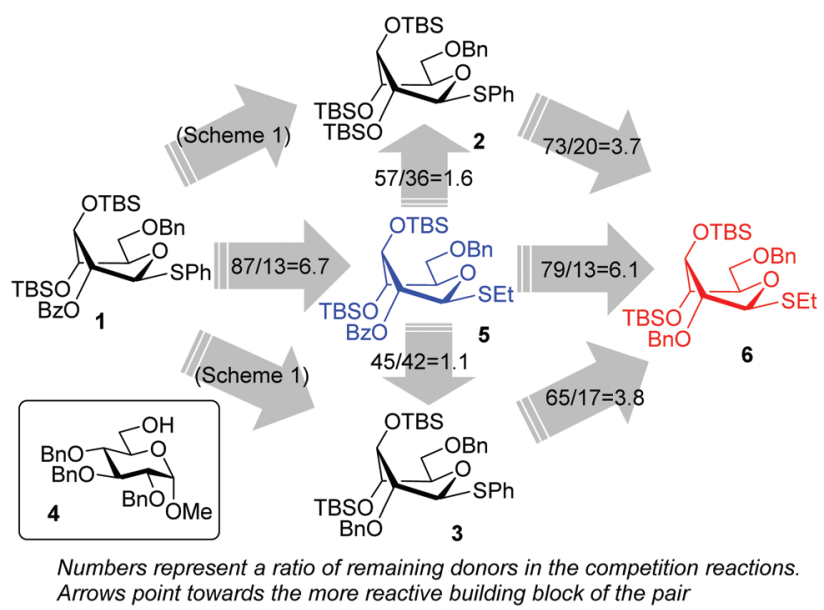

Scheme 2 The relative reactivity of S-phenyl versus S-ethyl glycosyl donors of the superarmed series. donor 6 is 3.7 times more reactive than the 2-O-TBS $\mathrm{SPh}$ donor $2 .{ }^{10}$

Encouraged by the first series of competition experiments, we decided to investigate the new hybrid donor 5 in the context of other SEt donors. For this study we obtained the anchimerically superarmed derivative 7 along with two conformationally superarmed donors 8 and 9, equipped with 6-O-benzoyl and 2,6-di-O-benzoyl protections, respectively. The first competition experiment that was conducted between donors 5 and 7 provided a very impressive reactivity difference: donor 5 was 95 times more reactive than donor 7 (Scheme 3). This result is more indicative of the superior reactivity of $\mathbf{5}$ than the poor reactivity of 7 . The latter donor is still superarmed because it is much more reactive than its per-benzylated counterpart. In addition, donor 7 is 2.2 times more reactive than the previously developed hybrid SPh donor 1 . Moreover, compound 7 is also 2.3 times more reactive than the conformationally superarmed SEt donor 8 equipped with two benzoyl groups at O-2 and O-6.

A comparison of donors $\mathbf{5}$ and $\mathbf{8}$ showed a very significant deactivating effect of 6-O-benzoyl in comparison with 6-O-benzyl, these groups being the only structural difference between the two donors. ${ }^{13}$ Thus, the 6-O-benzyl donor 5 was 97 times more reactive than its 6-O-benzoylated counterpart 8. Donor 5 was also found to be 5.3 times more reactive than donor 9 with reverse positioning of the benzyl and benzoyl substituents: 2-O-benzyl, 6-O-benzoyl.

With this comprehensive set of competition experiments, we began investigating the glycosyl donor properties of compounds 5-8 with the model acceptor 4. After screening a number of promoters for the activation of thioglycosides, we chose NIS/TfOH and DMTST. These reaction conditions offered a good balance of reactivity, selectivity and yield. Other promoters, including iodine which was successfully used in our previous study of anchimerically superarmed SEt donors, led to decreased yields resulting from high rates of major side reactions: TBS cleavage and/or SEt hydrolysis.

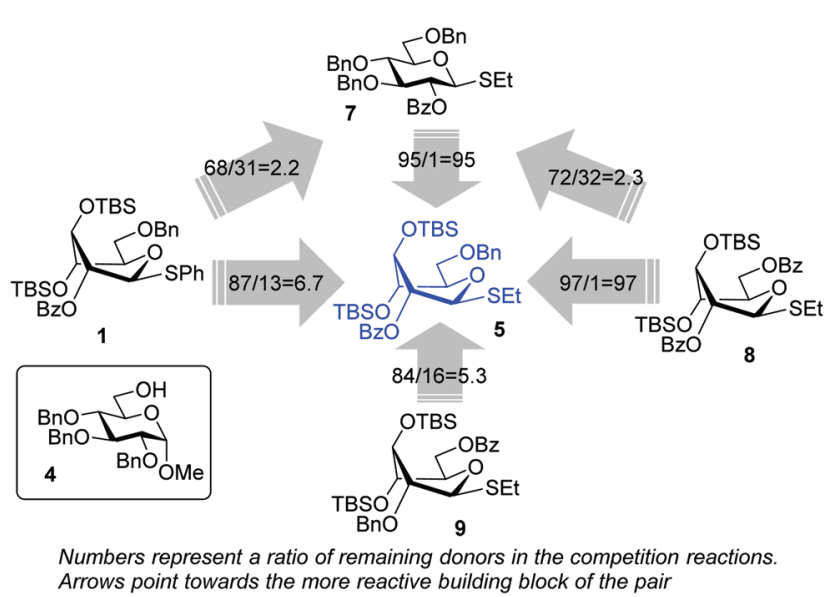

Scheme 3 The effect of conformational and electronic superarming in a series of $S$-ethyl glycosyl donors. 
Thus, NIS/TfOH-promoted coupling between donor $\mathbf{5}$ and acceptor 4 swiftly (20 min) produced disaccharide 10 in $83 \%$ yield and complete $\beta$-stereoselectivity (entry 1 , Table 1 ).

Practically the same outcome was achieved in the DMTSTpromoted reaction listed in entry 2 . NIS/TfOH-promoted activation of donor 6 produced disaccharide 11 in $81 \%$ yield (entry 3 ). In this case, the reaction was non-stereoselective due to the absence of neighboring group participation. In this case, DMTST was less effective and the TBS protecting groups showed a high propensity to cleavage. As a result, disaccharide 11 was obtained in a poor yield of $21 \%$ (entry 4 ). The outcome of this reaction could be improved (44\% yield) using only a slight excess of DMTST (1.3 equiv.).

Glycosidation of the anchimerically superarmed donor 7 was successful in the case of either NIS/TfOH or DMTST-

Table 1 Glycosylation of acceptor 4 with different superarmed SEt donors
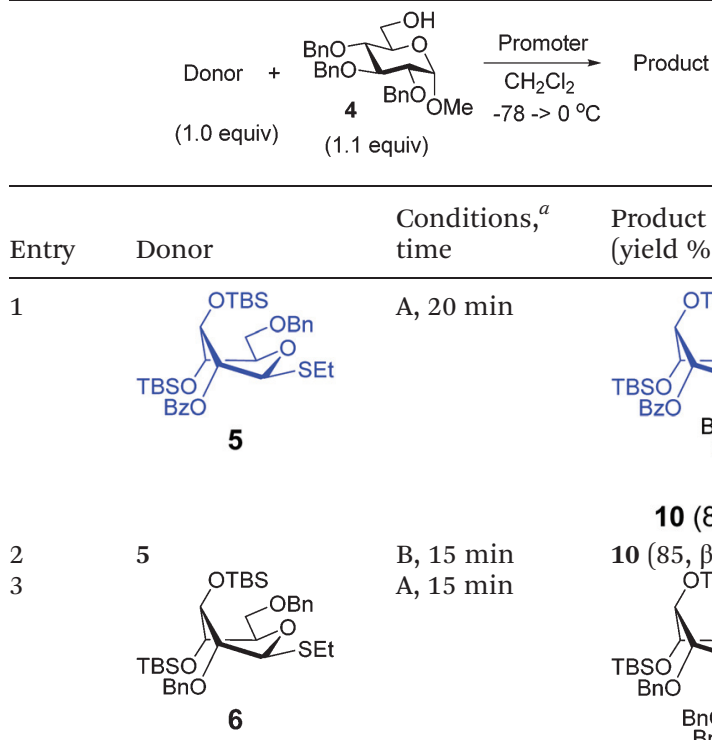

\section{Conditions, ${ }^{a} \quad$ Product}

time (yield $\% \alpha / \beta$ ratio)

A, 20 min

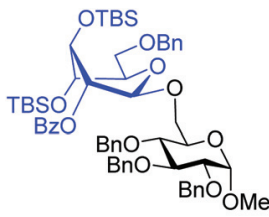

10 (83, $\beta$-only)

B, 15 min

A, 15 min

10 (85, $\beta$-only)

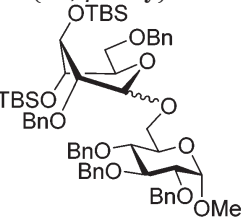

$11(81,1.0 / 1)$

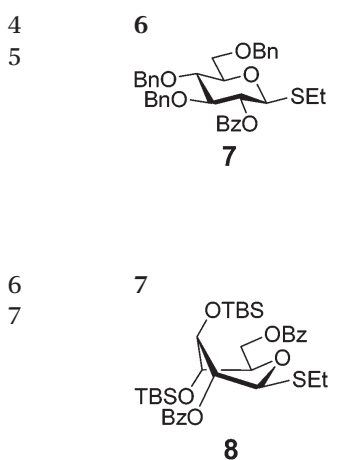

B, $10 \mathrm{~min}$

A, 30 min

$11(21,0.9 / 1)^{b}$

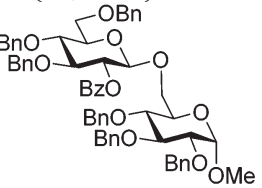

12 (82, $\beta$-only)

B, 20 min

A, 30 min

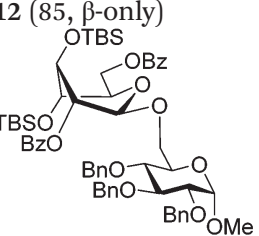

13 (85, $\beta$-only)

${ }^{a}$ Conditions A: NIS/TfOH (1.3 equiv.), $3 \AA$ mol sieves; B: DMTST (2.0 equiv.), $4 \AA$ mol sieves. ${ }^{b}$ The yield is impacted by fair stability of the TBS groups (see text).

promoted activation, and disaccharide 12 was obtained with complete $\beta$-stereoselectivity in 82 or $85 \%$ yield, respectively (entries 5 and 6). In case of donor 8, only NIS/TfOH gave a practical result, whereas DMTST showed a high level of competing processes. Thus, NIS/TfOH-promoted activation of 8 produced disaccharide $\mathbf{1 3}$ in $85 \%$ yield and complete $\beta$-stereoselectivity (entry 7). The conformational properties of disaccharide $\mathbf{1 0}$ were studied using X-ray crystallography (Fig. 1). The crystals of $\mathbf{1 0}$ were obtained by slowly evaporating a mixture of $\mathrm{MeOH} /$ water. The skew-boat conformation of disaccharide 10 was deduced from the X-ray data and was consistent with the altered coupling constants obtained from its ${ }^{1} \mathrm{H}$ NMR spectrum (Fig. 1).

Using a series of glycosyl donors of differential reactivity, we began studying the applicability of this method to the onepot oligosaccharide synthesis. ${ }^{14}$ With a number of different concepts for the one-pot synthesis, we chose the one-pot/ one-addition method wherein all of the building blocks are present from the beginning. Invented by Kahne, ${ }^{15}$ and further explored by Fraser-Reid ${ }^{16}$ and Bols, ${ }^{7 a}$ this approach requires fine tuning of the reactivity to differentiate all of the reaction components. The general idea underpinning this approach is that the more reactive donor will react with the more reactive acceptor (hydroxyl). Subsequently, the second-step coupling will involve coupling between the less reactive donor and the less reactive acceptor.

With these considerations, we chose highly reactive donor $\mathbf{5}$ to couple with the reactive $6-\mathrm{OH}$ in benzylated building block
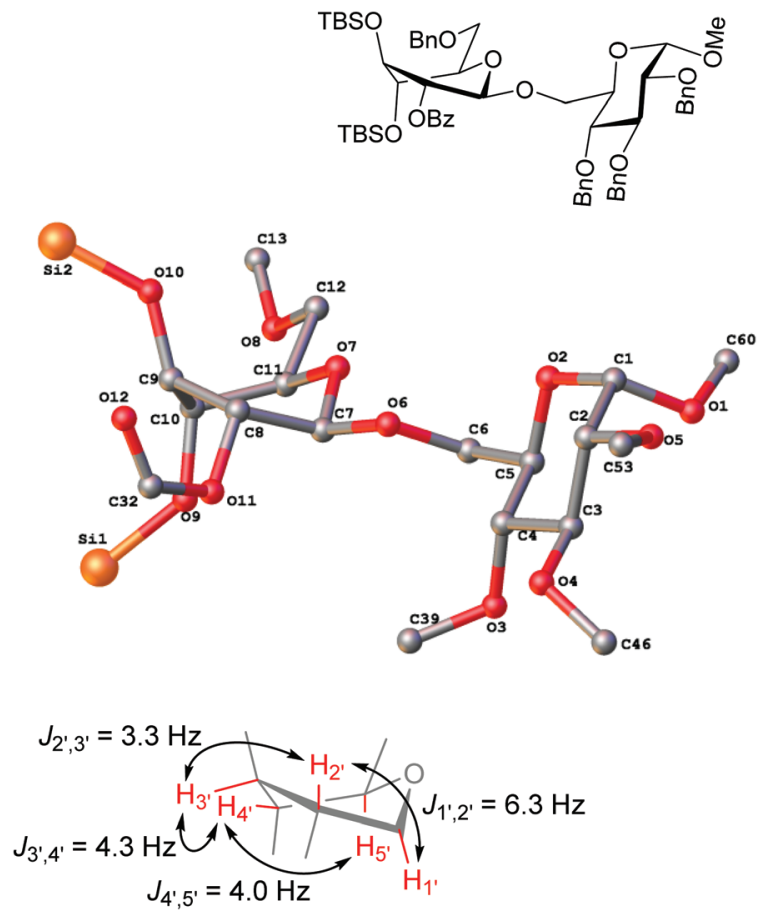

Fig. 1 The X-ray structure of disaccharide 10 (hydrogens and protecting groups have been omitted for clarity; refer to the ESI $\dagger$ for complete $\mathrm{X}$-ray structure and data). 
14 equipped with the anomeric SEt group. A fast first-step reaction will permit the sequential (rather than competitive) activation of the SEt leaving group of the intermediate disaccharide to react with the less reactive acceptor 15 (Scheme 4). Building block $\mathbf{1 4}$ is the key reaction component in the mixture because it can react with both compounds; firstly as the more reactive acceptor and then as the less reactive donor. The role of the highly reactive superarmed donor is also essential to ensure that the first coupling step is swift. The synthesis of trisaccharide $\mathbf{1 6}$ was conducted by mixing together building blocks 5, 14 and 15 and adding NIS/TfOH. As a result, compound 16 was obtained via one-pot synthesis in $42 \%$ yield and high stereoselectivity $(\alpha / \beta=14 / 1$, Scheme 4). A substantial quantity of cross-coupled disaccharide resulting from the reaction between $\mathbf{5}$ and $\mathbf{1 5}$ indicated that the reactivity difference between primary hydroxyls in $\mathbf{1 5}$ and $\mathbf{1 6}$ is insufficient to ensure effective one-pot coupling. A simple competition experiment set up between the two acceptors and donor 5 showed that $\mathbf{1 4}$ is only 1.6 times more reactive than $\mathbf{1 5}$ (Scheme 5, see the $\mathrm{ESI} \dagger$ for details).

To improve the outcome of the one-pot synthesis we prepared secondary acceptor $\mathbf{1 7}$, which was deactivated by the surrounding benzoyl substituents. ${ }^{17}$ The competition experiment showed that benzylated primary acceptor 14 is 10.1 times more reactive than its benzoylated secondary counterpart 17 (Scheme 5). Theorizing that this reactivity difference would be sufficient, we set up the synthesis of trisaccharide 18 from

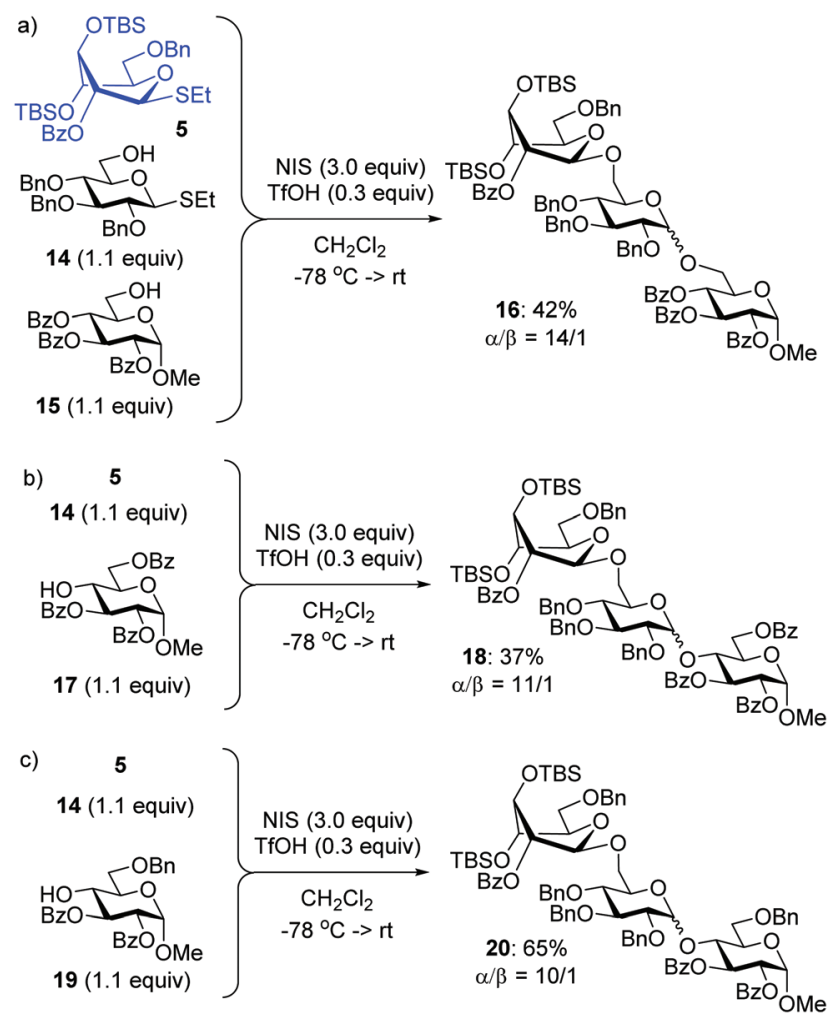

Scheme 4 One-pot one-addition synthesis of trisaccharides 16, 18 and 20.

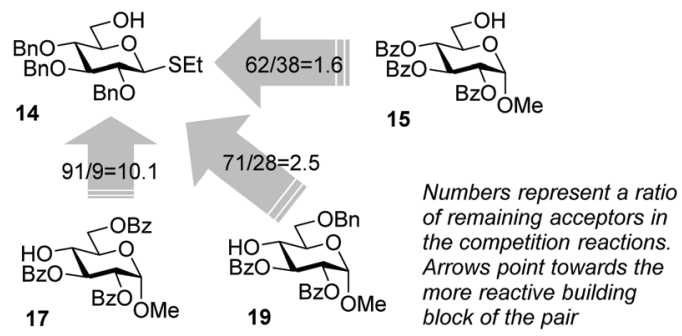

Scheme 5 The relative reactivity of glycosyl acceptors 14, 15, 17 and 19.

building blocks 5, 14 and 17 that were mixed and NIS/TfOH solution that was added. As a result, trisaccharide 18 was obtained via a one-pot synthesis in $37 \%$ yield and high stereoselectivity $(\alpha / \beta=11 / 1$, Scheme 4$)$. No cross-coupled disaccharide was found in the reaction mixture, but attempts to push the reaction to completion promoted competitive TBS group hydrolysis. In a further search of suitable building blocks for the one-pot synthesis, we obtained acceptor 19 benzylated at C-6. This acceptor is only 2.5 times less reactive than its perbenzylated primary counterpart 14 (Scheme 5). Nevertheless, this reactivity difference was sufficient for the synthesis of trisaccharide 20, which was produced in a good yield of $65 \%$ and high stereoselectivity $(\alpha / \beta=10 / 1$, Scheme 4$)$, showing the utility of this approach and also the necessity to fine-tune all of the reaction components.

In conclusion, we have developed a series of superarmed SEt glycosyl donors that were applied to stereoselective glycosylations and multi-step oligosaccharide synthesis in one pot. Further application of these highly reactive compounds for the glycosylation of various glycosyl acceptors in solution and on solid supports is currently underway in our laboratories.

\section{Acknowledgements}

This work was supported by a grant from the National Institute of General Medical Sciences (GM111835). Funding from the National Science Foundation (MRI, CHE-0420497) for the purchase of the ApexII diffractometer is acknowledged. We thank Dr Rensheng Luo (UM - St Louis) for help with acquiring spectral data using a $600 \mathrm{MHz}$ NMR spectrometer that was purchased thanks to the NSF (award CHE-0959360). Dr Winter and Mr Kramer (UM - St Louis) are thanked for the HRMS determinations.

\section{Notes and references}

1 (a) B. Capon, Chem. Rev., 1969, 69, 407-496; (b) D. Crich, Acc. Chem. Res., 2010, 43, 1144-1153; (c) L. K. Mydock and A. V. Demchenko, Org. Biomol. Chem., 2010, 8, 497-510; (d) S. C. Ranade and A. V. Demchenko, J. Carbohydr. Chem., 2013, 32, 1-43; (e) T. G. Frihed, M. Bols and C. M. Pedersen, Chem. Rev., 2015, 115, 4963-5013. 
2 (a) X. Zhu and R. R. Schmidt, Angew. Chem., Int. Ed., 2009, 48, 1900-1934; (b) S. S. Nigudkar and A. V. Demchenko, Chem. Sci., 2015, 6, 2687-2704.

3 (a) J. T. Smoot and A. V. Demchenko, Adv. Carbohydr. Chem. Biochem., 2009, 62, 161-250; (b) C. H. Hsu, S. C. Hung, C. Y. Wu and C. H. Wong, Angew. Chem., Int. Ed., 2011, 50, 11872-11923; (c) P. H. Seeberger, Acc. Chem. Res., 2015, 48, 1450-1463.

4 (a) D. R. Mootoo, P. Konradsson, U. Udodong and B. Fraser-Reid, J. Am. Chem. Soc., 1988, 110, 5583-5584; (b) B. Fraser-Reid, Z. Wu, U. E. Udodong and H. Ottosson, J. Org. Chem., 1990, 55, 6068-6070; (c) B. Fraser-Reid, U. E. Udodong, Z. F. Wu, H. Ottosson, J. R. Merritt, C. S. Rao, C. Roberts and R. Madsen, Synlett, 1992, 927-942 and references therein.

5 (a) P. Grice, S. V. Ley, J. Pietruszka, H. W. M. Priepke and E. P. E. Walther, Synlett, 1995, 781-784; (b) N. L. Douglas, S. V. Ley, U. Lucking and S. L. Warriner, J. Chem. Soc., Perkin Trans. 1, 1998, 51-65; (c) Z. Zhang, I. R. Ollmann, X. S. Ye, R. Wischnat, T. Baasov and C. H. Wong, J. Am. Chem. Soc., 1999, 121, 734-753; (d) T. K. Ritter, K.-K. T. Mong, H. Liu, T. Nakatani and C.-H. Wong, Angew. Chem., Int. Ed., 2003, 42, 4657-4660; (e) Y. Hsu, X. A. Lu, M. M. Zulueta, C. M. Tsai, K. I. Lin, S. C. Hung and C. H. Wong, J. Am. Chem. Soc., 2012, 134, 4549-4552; (f) Reactivity Tuning in Oligosaccharide Assembly, ed. B. Fraser-Reid and J. C. Lopez, Springer-Verlag, BerlinHeidelberg, 2011.

6 H. D. Premathilake and A. V. Demchenko, in Topics in Current Chemistry: Reactivity Tuning in Oligosaccharide Assembly, ed. B. Fraser-Reid and J. C. Lopez, Springer-Verlag, Berlin-Heidelberg, 2011, vol. 301, pp. 189-221.

7 (a) H. H. Jensen, C. M. Pedersen and M. Bols, Chem. - Eur. J., 2007, 13, 7576-7582; (b) C. M. Pedersen,
L. U. Nordstrom and M. Bols, J. Am. Chem. Soc., 2007, 129, 9222-9235; (c) C. M. Pedersen, L. G. Marinescu and M. Bols, Chem. Commun., 2008, 2465-2467; (d) M. Heuckendorff, C. M. Pedersen and M. Bols, Chem. - Eur. J., 2010, 16, 13982-13994; (e) C. M. Pedersen, L. G. Marinescu and M. Bols, C. R. Chim., 2010, 14, 17-43.

8 M. N. Kamat and A. V. Demchenko, Org. Lett., 2005, 7, 3215-3218.

9 (a) L. K. Mydock and A. V. Demchenko, Org. Lett., 2008, 10, 2103-2106; (b) L. K. Mydock and A. V. Demchenko, Org. Lett., 2008, 10, 2107-2110; (c) H. D. Premathilake, L. K. Mydock and A. V. Demchenko, J. Org. Chem., 2010, 75, 1095-1100.

10 M. Heuckendorff, H. D. Premathilake, P. Pornsuriyasak, A. Ø. Madsen, C. M. Pedersen, M. Bols and A. V. Demchenko, Org. Lett., 2013, 15, 4904-4907.

11 (a) M. Lahmann and S. Oscarson, Can. J. Chem., 2002, 80, 889-893; (b) J. P. Yasomanee and A. V. Demchenko, Chem. - Eur. J., 2015, 21, 6572-6581.

12 J. M. Kuester and I. Dyong, Justus Liebigs Ann. Chem., 1975, 2179-2189.

13 T. Schmidt and R. Madsen, Eur. J. Org. Chem., 2007, 39353941.

14 A. R. Parameswar and A. V. Demchenko, in Progress in the synthesis of complex carbohydrate chains of plant and microbial polysaccharides, ed. N. E. Nifantiev, Transworld Res. Network, Kerala, 2009, pp. 463-488.

15 S. Raghavan and D. Kahne, J. Am. Chem. Soc., 1993, 115, 1580-1581.

16 B. Fraser-Reid, J. C. Lopez, K. V. Radhakrishnan, M. V. Nandakumar, A. M. Gomez and C. Uriel, Chem. Commun., 2002, 2104-2105.

17 (a) M. Martín-Lomas, M. B. Cid and F. Alfonso, Synlett, 2005, 2052-2056; (b) S. Kaeothip, S. J. Akins and A. V. Demchenko, Carbohydr. Res., 2010, 345, 2146-2150. 